\title{
Biocompósitos de Matriz Glioxal-Fenol Reforçada com Celulose Microcristalina
}

\author{
Elaine C. Ramires, Jackson D. Megiatto Jr. \\ Instituto de Química de São Carlos, USP e Unité Sciences du Bois et des Biopolymères, Université Bordeaux 1 \\ Christian Gardrat, Alain Castellan \\ Unité Sciences du Bois et des Biopolymères, Université Bordeaux 1 \\ Elisabete Frollini
Instituto de Química de São Carlos, USP
}

Resumo: Glioxal pode ser obtido a partir de biomassa (como da oxidação de lipídeos) e não é tóxico ou volátil, tendo sido por isso utilizado no presente trabalho como substituto de formaldeído na preparação de resina fenólica do tipo novolaca, sendo usado como catalisador o ácido oxálico, que também pode ser obtido de fontes renováveis. A resina glioxal-fenol foi utilizada na preparação de compósitos reforçados com celulose microcristalina (CM, 30, 50 e 70\% em massa), uma celulose com elevada área superficial. As imagens de microscopia eletrônica de varredura (MEV) das superfícies fraturadas demonstraram que os compósitos apresentaram boa interface reforço/matriz, consequência da elevada área superficial da $\mathrm{CM}$ e presença de grupos polares (hidroxilas) tanto na matriz como na celulose, o que permitiu a formação de ligações hidrogênio, favorecendo a compatibilidade entre ambas. A análise térmica dinâmico-mecânica (DMTA) demonstrou que todos os compósitos apresentaram elevado módulo de armazenamento à temperatura ambiente. Além disso, o compósito reforçado com $30 \%$ de CM apresentou baixa absorção de água, comparável à do termorrígido fenólico, que é utilizado em escala industrial. Os resultados demonstraram que compósitos com boas propriedades podem ser preparados usando elevada proporção de materiais obtidos de biomassa.

Palavras-chave: Biocompósitos, glioxal, resina fenólica, celulose microcristalina.

\section{Biobased Composites from Glyoxal-Phenol Matrices Reinforced with Microcrystalline Cellulose}

\begin{abstract}
Glyoxal, which can be obtained from biomass (as by lipids oxidation), is non-toxic and non-volatile. It was used as a substitute of formaldehyde, which does not have these properties, in the synthesis of a novolac-type phenolic resin, using oxalic acid as a catalyst, which can also be obtained from renewable sources. The glyoxal-phenol resin was used in the preparation of composites reinforced with microcrystalline cellulose (MCC 30, 50, and 70\% w/w). Scanning electron microscopy (SEM) images of the fractured surfaces showed that the composites presented a good reinforcement/matrix interface. This can be attributed to the high surface area of the MCC and also to the presence of polar groups (hydroxyl) in both cellulose and matrix, which allowed the formation of hydrogen bonds, leading to a good adhesion between the components present at the interface. Dynamic mechanical thermoanalysis (DMTA) showed that all of the obtained composites have high storage modulus at room temperature. Moreover, the composite reinforced with $30 \%$ of MCC showed the lowest water absorption, almost the same as that of the phenolic thermoset, which is used in industrial applications. The results showed that composites with good properties can be prepared using high proportions of materials obtained from biomass.
\end{abstract}

Keywords: Biobased composites, glyoxal, phenolic resin, microcrystalline cellulose.

\section{Introdução}

Atualmente, o desenvolvimento de compósitos baseados em constituintes de origem natural é considerado primordial, tanto pela potencial aplicação tecnológica destes biocompósitos, como pela diminuição dos impactos ambientais resultantes da aplicação destes materiais ${ }^{[1-3]}$.

Resinas fenólicas são utilizadas como materiais de isolamento térmico, pós de moldagem, resinas laminadas, adesivos, recobrimento de superfícies, impregnantes e

compósitos $^{[4-6]}$. Isto ocorre devido às suas excelentes propriedades como estabilidade dimensional, resistência diante de vários solventes, estabilidade térmica, atuação como retardante de chama ${ }^{[7,8]}$, dentre outros fatores. Comparada a outros materiais poliméricos, as resinas fenólicas são as mais difíceis de incendiar, liberam menor quantidade de fumaça e gases tóxicos e geram a mais elevada quantidade de carbono como resíduo, o que retarda ainda mais a queima ${ }^{[5]}$. 
A resina fenólica do tipo novolaca é obtida pela reação em meio ácido de excesso de fenol com formaldeído ${ }^{[9]}$, sendo estes reagentes obtidos em larga escala de fontes não renováveis. Assim, a substituição desses reagentes por equivalentes originados de fontes não fósseis é uma alternativa interessante, tanto do ponto de vista econômico como ambiental ${ }^{[4,8]}$. Adicionalmente, a substituição do formaldeído por outros aldeídos obtidos de fontes renováveis pode também eliminar a potencial emissão de formaldeído durante o uso das resinas fenólicas ${ }^{[1,10]}$. O ácido oxálico, que foi utilizado no presente trabalho como catalisador na síntese das resinas fenólicas do tipo novolaca, pode ser obtido de fontes renováveis, como folhas, caules, flores e raízes de plantas $^{[11]}$. O glioxal (OHC-CHO) é um dialdeído que pode ser obtido de diversas fontes naturais, como a partir da oxidação de lipídeos. Os dois grupos carbonila adjacentes conferem ao glioxal alta reatividade ${ }^{[12]}$, sendo o mesmo não tóxico e não volátil, sendo estas as principais vantagens da utilização do glioxal, quando comparado ao formaldeído ${ }^{[13]}$.

A celulose é o material de origem vegetal mais abundante na Terra, conferindo rigidez à parede celular das plantas. Corresponde a um polissacarídeo de cadeia linear cuja unidade repetitiva é a celobiose. A celulose microcristalina $(\mathrm{CM})$ é obtida em larga escala a partir de polpa de madeira, sendo as regiões não cristalinas removidas por hidrólise ácida, apresentando por isso elevado índice de cristalinidade $^{[14]}$. A CM pode ser composta de microfibras fragmentadas e partículas que possuem entre 5 e $10 \mathrm{~nm}$ de diâmetro e comprimento de $100 \mathrm{~nm}$ a alguns micrômetros, o que corresponde a uma elevada área superficial. $\mathrm{O}$ uso de agentes de reforço com área superficial elevada é considerado como um método para obter melhores interações entre matriz e reforço, resultando em boas propriedades mecânicas, além de estabilidade dimensional e térmica ${ }^{[14]}$. A presença dos grupos polares (hidroxilas) tanto na matriz fenólica (Figura 1a) como na celulose (Figura 1b) favorecem a compatibilidade entre ambas, resultando em melhor interação na interface celulose/matriz e, consequentemente, no melhoramento das propriedades dos compósitos obtidos ${ }^{[15]}$.

Em trabalhos anteriores ${ }^{[4,16]}$ o fenol foi parcialmente substituído por lignina e tanino, duas macromoléculas naturais que apresentam grupos fenólicos em suas estruturas, na preparação de resinas fenólicas do tipo resol (reação em meio básico). Estas resinas foram utilizadas em compósitos reforçados com fibras lignocelulósicas e celulósicas de sisal e CM. No presente trabalho, o glioxal foi usado como substituto total do formaldeído na síntese de resinas fenólicas do tipo novolaca (reação em meio ácido). Estas resinas foram então utilizadas no preparo de compósitos reforçados com celulose mcrocristalina em proporções variadas, produzindo biocompósitos com elevada proporção de reagentes originados de biomassa.

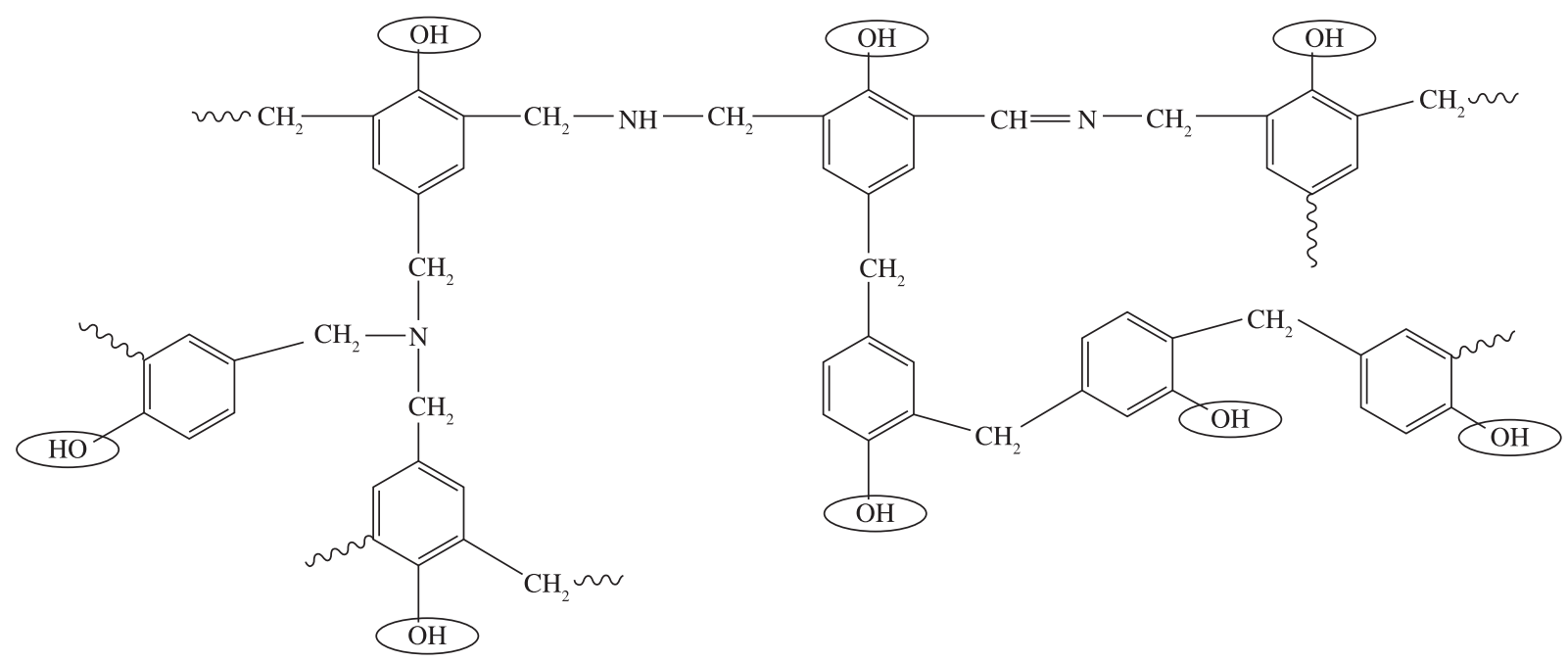

(a)

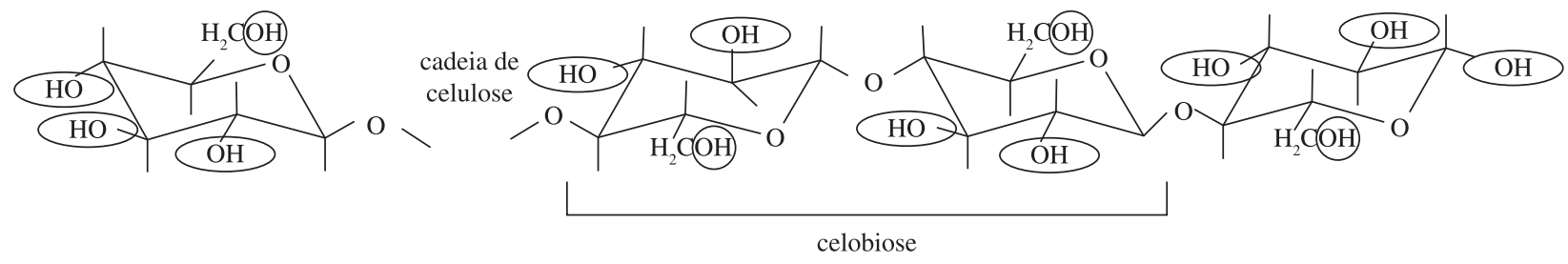

(b)

Figura 1. (a) Representação esquemática de parte da estrutura da matriz fenólica do tipo novolaca entrecruzada; (b) Estrutura das unidades presentes na cadeia de celulose. 


\section{Experimental}

\section{Síntese do pré-polímero glioxal-fenol e preparação dos compósitos}

O pré-polímero foi sintetizado reagindo glioxal e fenol na proporção molar de 0,23:1,0 na presença de ácido oxálico como catalisador $(3,5 \%$ em massa com relação ao glioxal) durante 7 horas a $125{ }^{\circ} \mathrm{C}$. Após a evaporação da água, usando um evaporador rotativo, o agente de entrecruzamento (hexametilenotetramina-HMTA) foi misturado à resina. A adição da celulose microcristalina (CM, gentilmente doada pela Valdequímica, São Paulo, SP) foi feita de duas formas diferentes: (I) a celulose foi adicionada ao meio reacional logo no início da preparação do pré-polímero, visando a ocorrência de uma possível hidrólise da celulose em meio ácido, o que leva à diminuição do tamanho médio de partículas (II) a celulose foi adicionada após a adição do agente acelerador de cura. Primeiramente foram preparados compósitos reforçados com 30\% de CM seguindo os métodos (I) e (II). Considerando que melhores resultados foram apresentados pelo compósito (I), conforme mostrado posteriormente neste texto, foram preparados compósitos reforçados com 50 e $70 \%$ de CM seguindo este método (I). A moldagem por compressão foi realizada segundo o ciclo de cura: $90{ }^{\circ} \mathrm{C} / 0,5$ hora $/ 0 \mathrm{t} ; 115^{\circ} \mathrm{C} / 1$ hora $/ 2 \mathrm{t} ; 140{ }^{\circ} \mathrm{C} / 1$ hora $/ 10 \mathrm{t}$; $160{ }^{\circ} \mathrm{C} / 1$ hora/ $16 \mathrm{t} ; 180{ }^{\circ} \mathrm{C} / 1,5$ hora $/ 16 \mathrm{t}$.

\section{Caracterização dos compósitos glioxal-fenol reforçados com celulose microcristalina}

A Análise Térmica Dinâmico-Mecânica (DMTA) foi realizada em equipamento DMA, modelo 2980 da TA Instruments, operando com a garra 3-point bending (modo de flexão), com freqüência de $1 \mathrm{~Hz}$, taxa de aquecimento de $2{ }^{\circ} \mathrm{C} /$ min de 30 a $230{ }^{\circ} \mathrm{C}$.

A Microscopia Eletrônica de Varredura (MEV) foi realizada em equipamento da marca Zeiss-Leica ${ }^{\circledR}$, modelo 440, aceleração de elétrons de $20 \mathrm{kV}$.

O Ensaio de Absorção de Água foi realizado segundo a norma ASTM D570 ${ }^{[17]}$, sendo as amostras imersas em água destilada, a temperatura ambiente, até a saturação. A porcentagem de aumento de massa (conteúdo de água) foi calculada por diferença de massa.

A Termogravimetria (TG) foi realizada em equipamento Shimadzu ${ }^{\circledR}$, modelo TGA-50, sob atmosfera de ar sintético (fluxo de $20 \mathrm{~mL} / \mathrm{min}$ ), taxa de aquecimento de $10{ }^{\circ} \mathrm{C} / \mathrm{min}$, de 25 a $800{ }^{\circ} \mathrm{C}$. A Calorimetria Exploratória Diferencial (DSC) foi realizada em equipamento Shimadzu ${ }^{\circledR}$, modelo DSC-50, aquecimento de 100 a $400{ }^{\circ} \mathrm{C}$ a $10{ }^{\circ} \mathrm{C} / \mathrm{min}$, sob atmosfera de ar sintético $(20 \mathrm{~mL} / \mathrm{min})$. As análises de TG e DSC foram realizadas sob atmosfera de ar sintético visando simular as condições usuais de aplicação do material.

\section{Resultados e Discussões}

A análise térmica dinâmico-mecânica fornece informações a respeito do módulo de elasticidade ou armazenamento (E'), do módulo de dissipação viscosa ou perda (E") e do amortecimento mecânico ou atrito interno ( $\left.\tan \delta=E^{\prime \prime} / E^{\prime}\right)$ de um material, quando sujeito a uma solicitação dinâmica. As propriedades dinâmicomecânicas dos compósitos são determinadas pelas propriedades de seus componentes, pela morfologia do sistema e pela natureza da interação entre os dois componentes. A Figura 2 apresenta as curvas de E', E" e tan $\delta v s$. temperatura dos compósitos glioxalfenol reforçados com 30, 50 e $70 \%$ de celulose microcristalina (CM), obtidos via métodos I e II (Experimental).

Todos os compósitos apresentaram elevado módulo de armazenamento na temperatura inicial da análise (temperatura ambiente) (Figura 2a). Esta análise não foi realizada para o termorrígido glioxal-fenol, pois, devido à fragilidade do termorrígido não reforçado, não foi possível preparar os corposde-prova com as dimensões especificadas para esta análise, o que indica que a presença de $\mathrm{CM}$ como reforço da matriz conferiu propriedades não presentes no termorrígido. O compósito reforçado com $30 \%$ de CM adicionada via método II apresentou menor módulo de armazenamento quando comparado ao compósito preparado via método I, embora a diferença não seja muito significativa. Isto foi indicativo de uma maior dissipação de energia na transferência de esforço na interface, indicando interação celulose/matriz mais fraca neste compósito (preparado via método II). Adicionalmente, neste compósito pode ter ocorrido um efeito plastificante, diminuindo E', devido à uma maior absorção de umidade (discutida na sequência deste texto). $\mathrm{O}$ aumento na proporção de $\mathrm{CM}$ utilizada nos compósitos glioxal-fenol resultou no aumento da rigidez do material. A celulose é um material de alta cristalinidade que pode agir como entrecruzador físico, o que pode aumentar consideravelmente a rigidez, e consequentemente o módulo dos compósitos ${ }^{[14]}$.

O compósito glioxal-fenol reforçado com $30 \%$ de $\mathrm{CM}$ apresentou módulo de perda menor que dos compósitos reforçados com 50 e $70 \%$ de $\mathrm{CM}$ (Figura 2b), indicando uma maior adesão da celulose à matriz nos compósitos reforçados com menor proporção de celulose. Quanto melhor a interface $\mathrm{CM} /$ matriz, mais eficiente é a transferência de carga e menor é a dissipação de energia e, portanto, menor é o valor de E".

Apesar da estrutura entrecruzada das matrizes termorrígidas, o entrecruzamento pode não ser completo e, portanto, podem ocorrer movimentações de segmentos de cadeias situados entre os pontos de entrecruzamento. Usando as curvas de $\tan \delta$ em função da temperatura é possível avaliar o valor da temperatura de transição vítrea $(\mathrm{Tg})$, que é em torno de $130^{\circ} \mathrm{C}$ para todos os compósitos (Figura 2c).

A Figura 3 apresenta as curvas TG, derivada primeira da TG (dTG) e DSC dos compósitos glioxal-fenol (CGF) reforçados com CM. Como todos os compósitos apresentaram comportamento térmico similar, somente serão apresentadas as curvas referentes aos compósitos reforçados com 30\% de celulose. Os compósitos apresentaram estabilidade térmica inferior à do termorrígido (Figura 3a), em consequência da 


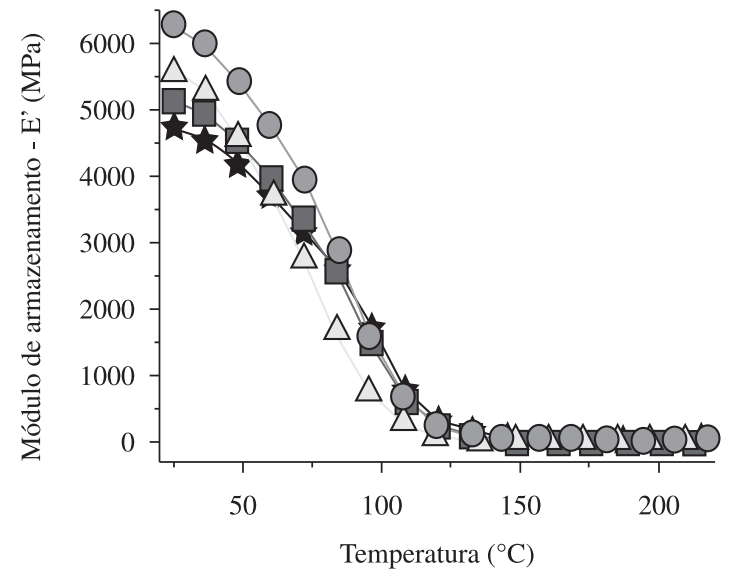

(a)

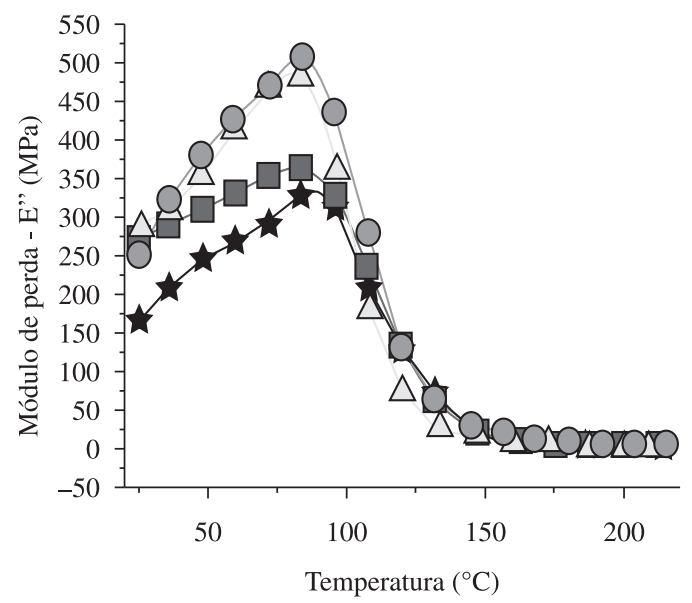

(b)

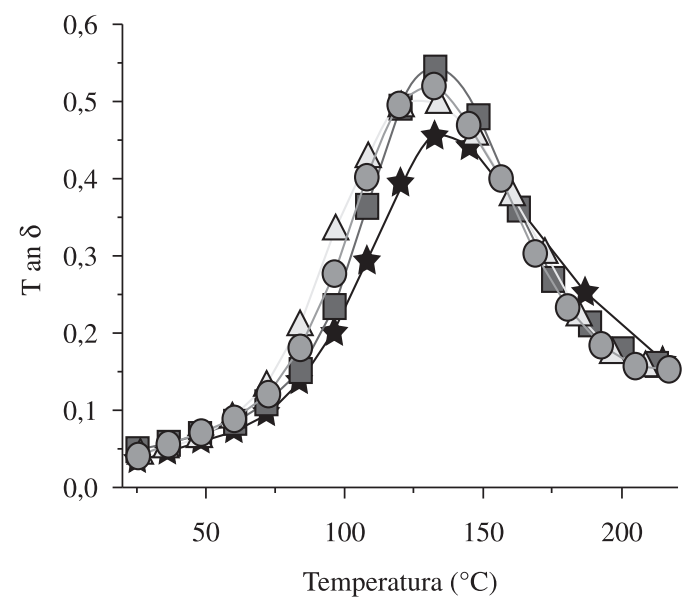

(c)
Figura 2. Curvas DMTA dos compósitos glioxal-fenol reforçados com 30, $50 \mathrm{e}$ $70 \%$ de CM. (a) E' versus temperatura; (b) E" versus temperatura; (c) $\tan \delta v s$. temperatura. Os compósitos foram obtidos via métodos I e II (Experimental).

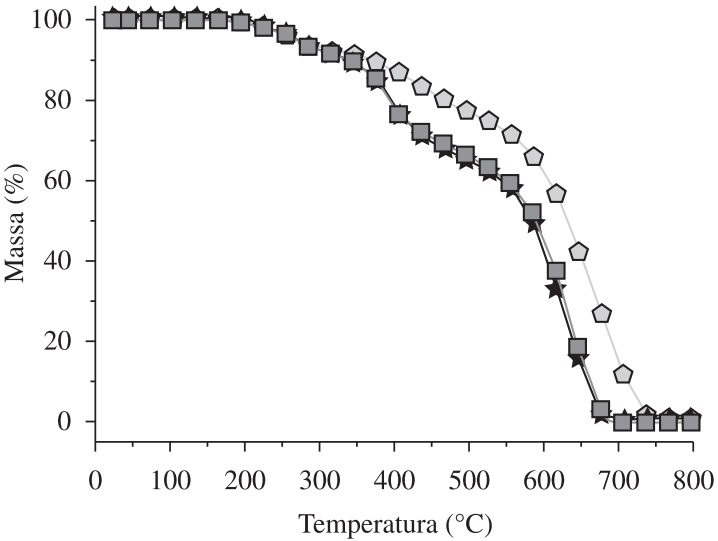

(a)

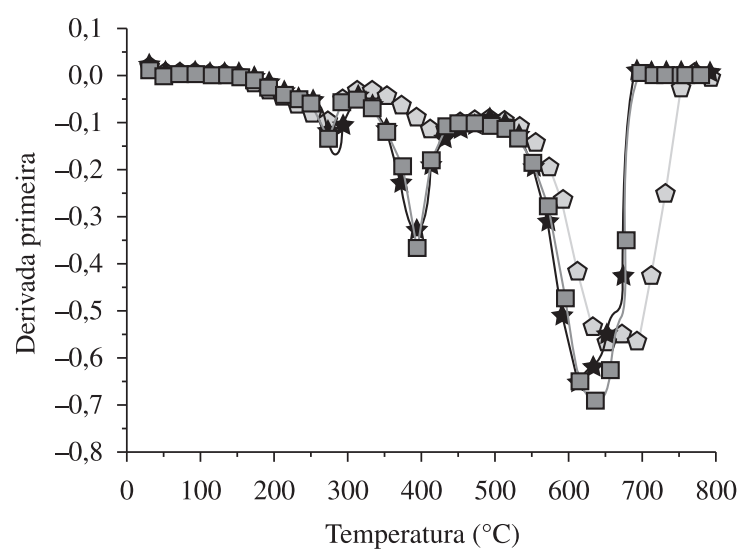

(b)

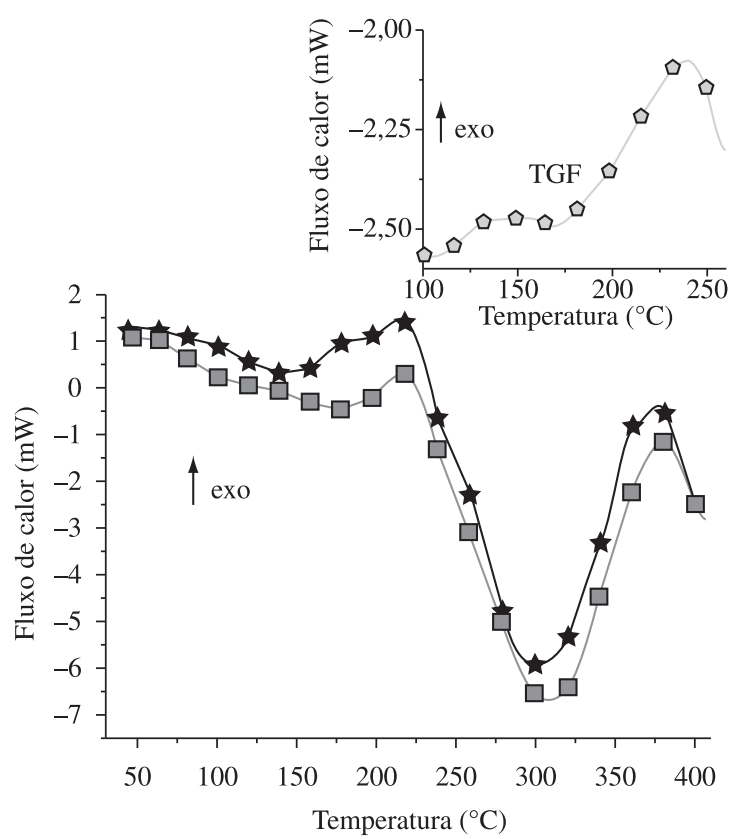

(c)

$\triangle$ TGF $\rightarrow$ CGF - 30\% CM(II) $\square-\mathrm{CGF}-30 \% \mathrm{CM}(\mathrm{I})$

Figura 3. Curvas (a) TG, (b) dTG e (c) DSC do termorrígido (TGF) e dos compósitos glioxal-fenol (CGF) reforçados com 30\% de celulose CM $(20 \mathrm{~mL} / \mathrm{min})$ e taxa de aquecimento de $10{ }^{\circ} \mathrm{C} / \mathrm{min}$. 
presença da celulose, que se decompõem em temperatura inferior à da matriz polimérica. Até $100{ }^{\circ} \mathrm{C}$ não foi observada perda de massa (Figura 3a), indicando que o termorrígido e os compósitos não absorveram quantidade significativa de umidade. Em torno de $270^{\circ} \mathrm{C}$ foi observada uma pequena perda de massa no termorrígido e nos compósitos, provavelmente devido à ocorrência de reações de cura residual, com liberação da água que volatilizou. A partir de $300{ }^{\circ} \mathrm{C}$ foram observadas perdas significativas de massa nos compósitos devido à decomposição térmica da celulose, sendo que a degradação máxima ocorreu em torno de $400{ }^{\circ} \mathrm{C}$ (Figura 3b). A partir de $600{ }^{\circ} \mathrm{C}$ foi observado o estágio de maior perda de massa, devido à decomposição da matriz glioxal-fenol.

As curvas DSC dos compósitos (Figura 3c) apresentaram um pico exotérmico em torno de $220^{\circ} \mathrm{C}$ possivelmente referente a prováveis reações de cura residual da matriz glioxal-fenol. Já a curva DSC do termorrígido apresentou dois picos exotérmicos referentes às reações de cura residual, em 150 e $240{ }^{\circ} \mathrm{C}$. Em torno de $300^{\circ} \mathrm{C}$ observou-se um pico endotérmico nas curvas dos compósitos que pode ser referente à volatilização de moléculas de baixa massa molar, provavelmente geradas pelo início da decomposição da celulose. Em torno de $350{ }^{\circ} \mathrm{C}$ foi observado um pico exotérmico devido a outras etapas de decomposição térmica da celulose presente nos compósitos. No geral, as reações de decomposição da celulose ocorrem pela clivagem de ligações glicosídicas, ligações C-H, C-O, C-C, assim como pela desidratação, descarboxilação e descarbonilação. A formação de água a partir da celulose ocorre em várias temperaturas, pois várias reações envolvidas na degradação deste polissacarídeo formam água. $\mathrm{O}$ produto mais abundante proveniente da degradação da celulose corresponde a levoglucosana, que é carbonizada em torno de $600{ }^{\circ} \mathrm{C}$, com a liberação de água ${ }^{[18]}$.
A Figura 4 apresenta as micrografias da fratura dos compósitos glioxal-fenol reforçados com $30 \%$ de CM, obtidos via métodos I e II (Experimental). Nas micrografias foi possível observar que o compósito em que a celulose foi adicionada no início da preparação da matriz (I) apresentou uma superfície mais homogênea (Figura 4a) comparado com os compósitos em que a celulose é adicionada antes da moldagem (II) (Figura 4d). No compósito preparado via método (I), a celulose estava totalmente aderida à matriz e recoberta por ela, permanecendo ligada à mesma após o ensaio de impacto (Figuras 4b e 4c). No compósito preparado via método (II) observou-se que a celulose não foi totalmente recoberta pela matriz (Figura 4e) e ainda ocorreu o arrancamento da celulose da matriz durante o ensaio de impacto (Figura 4f). A CM é constituída por microfibras fragmentadas e partículas, com comprimento variando de $100 \mathrm{~nm}$ a alguns micrômetros, conforme mencionado previamente.

A Figura 5 apresenta as micrografias da fratura dos compósitos glioxal-fenol reforçados com 50 e $70 \%$ de $\mathrm{CM}$, preparados via método (I). Nas imagens de MEV dos compósitos reforçados com 50 e $70 \%$ de CM observou-se a presença de diversas trincas na superfície fraturada destes compósitos (Figuras 5a e 5c). Observou-se ainda a presença de partículas de celulose bem aderida à matriz, porém outras foram arrancadas, demonstrando uma superfície mais heterogênea nesses compósitos (Figuras $5 \mathrm{~b}$ e $5 \mathrm{~d}$ ). $\mathrm{O}$ aumento na proporção de celulose pode ter levado a uma maior dificuldade na dispersão do reforço pela matriz.

A Figura 6 apresenta os resultados obtidos no ensaio de absorção de água do termorrígido e dos compósitos glioxalfenol reforçados com 30, 50 e $70 \%$ em massa de CM. O compósito em que a celulose foi adicionada no inicio da reação de obtenção do pré-polímero (I) foi o que apresentou a menor

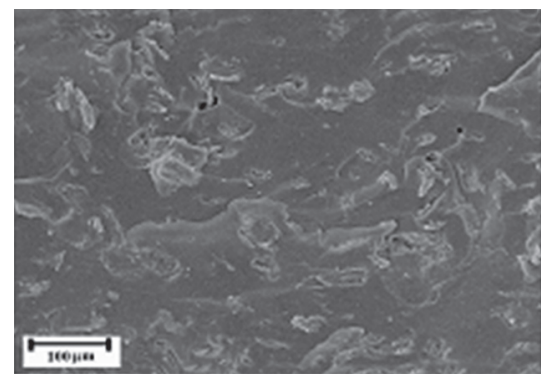

(a)

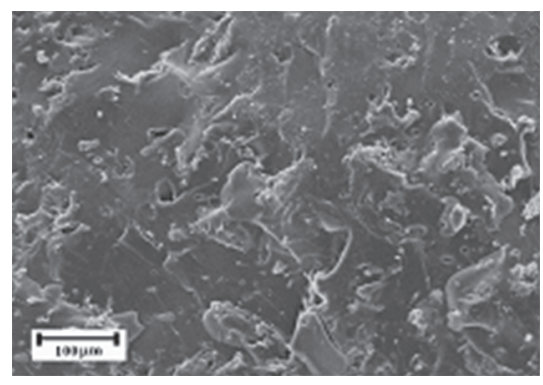

(d)

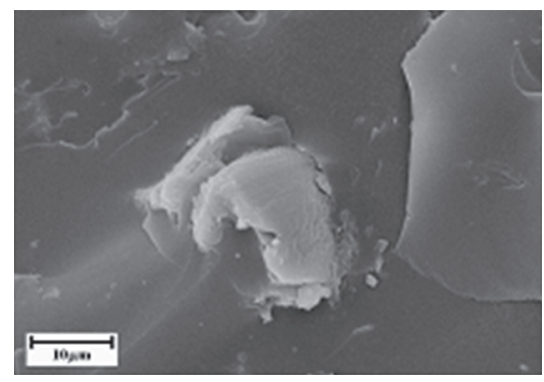

(b)

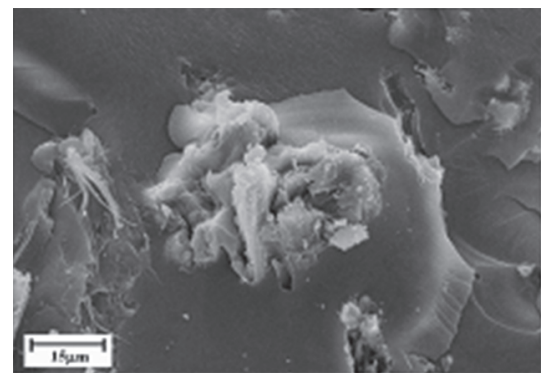

(e)

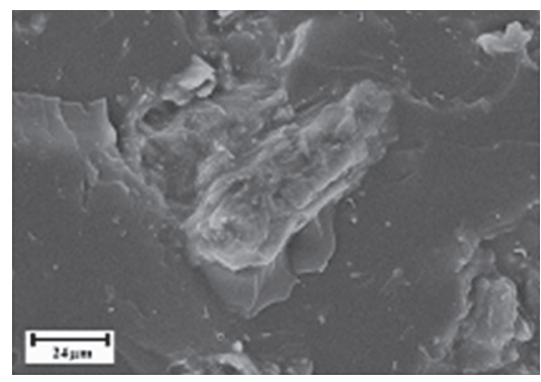

(c)

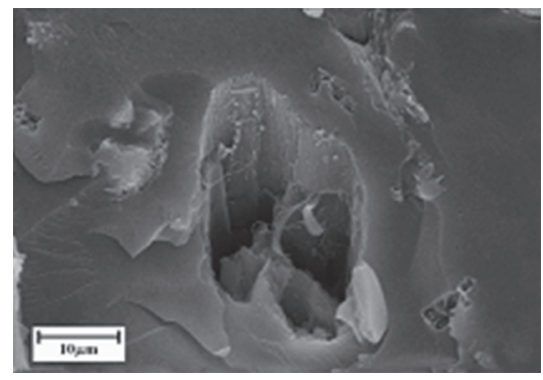

(f)

Figura 4. Imagens de MEV da superfície fraturada dos compósitos glioxal-fenol reforçados com 30\% de CM. (a), (b), (c) adicionada no início da reação (I) $(\times 500, \times 5000, \times 2000)$; (d), (e), (f) adicionada antes da moldagem (II) $(\times 500, \times 3000, \times 5000)$. 


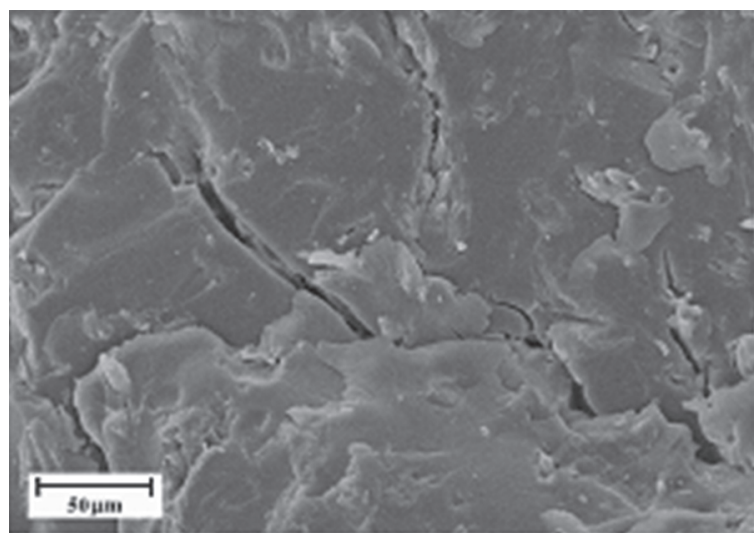

(a)

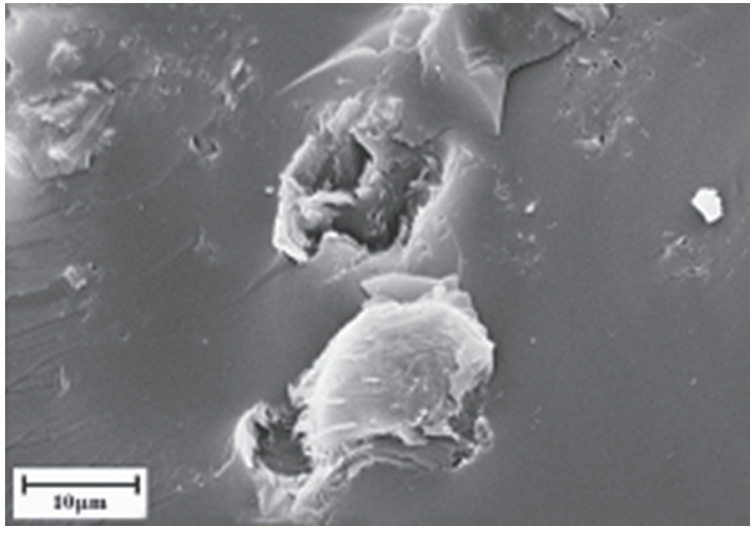

(b)

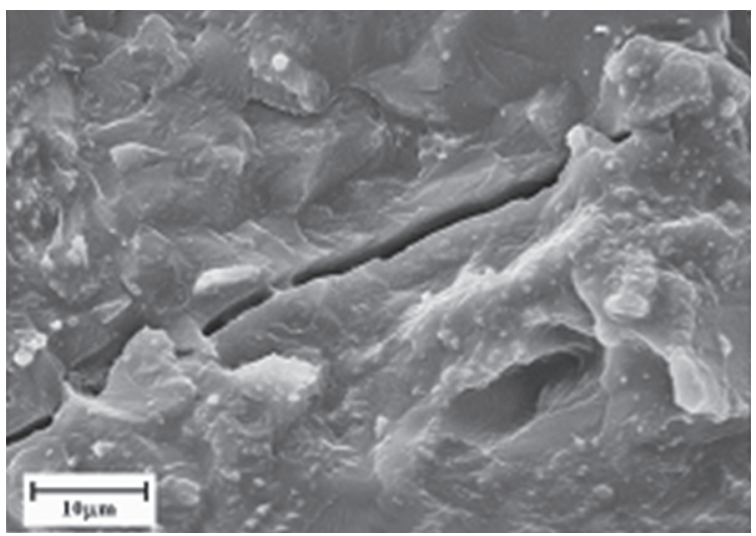

(c)

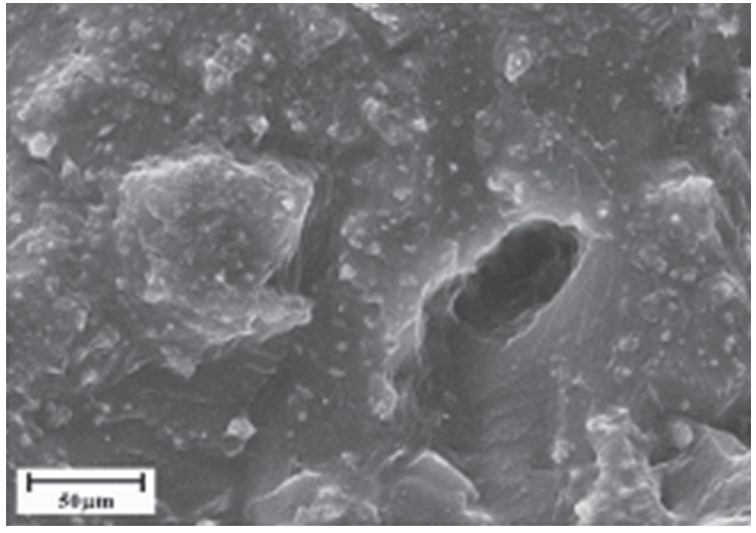

(d)

Figura 5. Imagens de MEV da superfície fraturada dos compósitos glioxal-fenol reforçado com (a), (b) 50\% de CM (×1000, ×5000); (c), (d) 70\% de CM $(\times 3000, \times 5000)$.

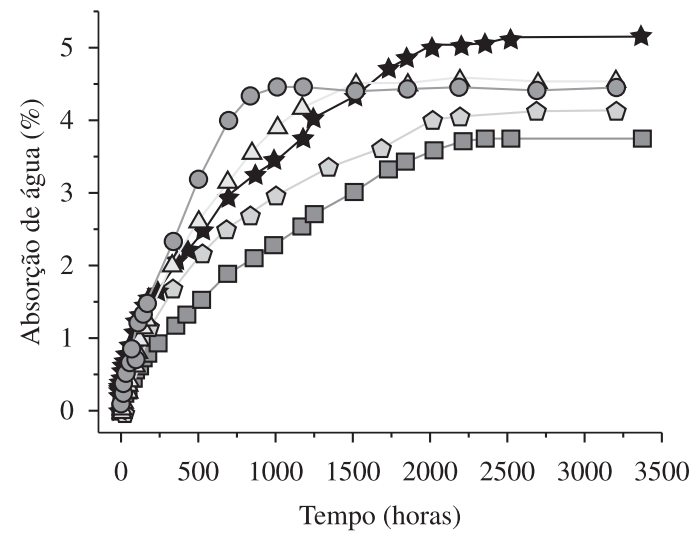

$\square$ TGF
$\star$ CGF - 30\% CM(II)
$\square$ CGF - 30\% CM(I)
$\triangle$ CGF - 50\% CM(I)
$\square$ CGF - $70 \%$ CM(I)

Figura 6. Resultado do ensaio de absorção de água do termorrígido (TGF) e dos compósitos glioxal-fenol (CGF) reforçados com 30\%, $50 \%$ e $70 \%$ de celulose CM.

absorção de água (Figura 6), demonstrando que ocorreu uma interação maior entre o reforço e a matriz, confirmando o que foi observado pelas imagens de MEV (Figura 4). A absorção de água neste compósito foi até mesmo menor que a do termorrígido glioxal-fenol (sem adição de agente de reforço, que é hidrofílico). Isto se deve provavelmente a maior quantidade de vazios e microfendas apresentados pelo termorrígido, que podem armazenar as moléculas de água, aumentando com isso a absorção de água deste material. Adicionalmente, no meio ácido em que o pré-polímero foi preparado, e que já continha a CM (método I), esta pode ser parcialmente hidrolisada (a água presente só é eliminada no final do processo), gerando partículas menores, o que facilitou a impregnação partícula/matriz, durante a etapa de moldagem, intensificando as interações na interface. Desta forma, o menor número de vazios presentes e menor capacidade de absorção de água de regiões cristalinas da celulose (devido ao empacotamento mais eficiente das cadeias, comparativamente à regiões não cristalinas) levam a menor absorção de água do material como um todo.

A absorção de água do compósito glioxal-fenol reforçado com $30 \%$ de CM preparado via método (I) foi muito próxima à do termorrígido fenólico (Figura 6 ${ }^{[4]}$, confirmando a maior higroscopicidade deste compósito, mencionada durante a discussão dos resultados de DMTA.

No compósito glioxal-fenol o formaldeído foi substituído por um aldeído obtido da biomassa e, ainda, o reforço utilizado em substituição de parte do termorrígido foi também de origem natural, gerando assim um biocompósito com alto teor de materiais obtidos de fontes renováveis, e que 
apresentou propriedades equivalentes, ou até superiores, a de materiais utilizados atualmente em escala industrial, ou seja, do termorrígido fenólico.

$\mathrm{O}$ aumento da quantidade de $\mathrm{CM}$ utilizada como reforço nos compósitos resultou no aumento da porcentagem de água absorvida, devido ao aumento da quantidade de grupos polares (hidroxilas) que podem interagir com as moléculas de água. Porém, observou-se que o aumento da absorção de água foi pequeno, pois a CM é composta por cadeias que, em sua maioria, se encontram em regiões cristalinas (índice de cristalinidade da celulose de partida $=83,3 \%$ ), em que a difusão de moléculas de água é dificultada. A difusão de água em compósitos pode ser avaliada a partir da modelo de difusão Fickiano, aplicando-se os dados obtidos no ensaio de absorção de água à Equação $1^{[19]}$.

$$
\log \frac{M_{t}}{M_{\infty}}=\log k+n \log t
$$

sendo que $\mathrm{M}_{\mathrm{t}}$ corresponde ao conteúdo de água a um tempo t; $\mathrm{M}_{\infty}$ corresponde ao conteúdo de água no equilíbrio; $\mathrm{k}$ e $\mathrm{n}$ correspondem a constantes. Além disso, a habilidade das moléculas de água em penetrar nos compósitos pode ser avaliada através do coeficiente de difusão (D) ${ }^{[19]}$, que pode ser obtido a partir da Equação 2:

$$
\frac{M_{t}}{M_{\infty}}=\frac{4}{L}\left(\frac{D}{\pi}\right)^{1 / 2} t^{1 / 2}
$$

sendo que L corresponde a espessura da amostra.

Os valores de $\mathrm{n}$ se situaram em torno de 0,4 , o que, somado a linearidade das curvas no intervalo de tempo inicial do experimento permitiu considerar que o modelo de Fick poderia ser usado. Os valores baixos de $\mathrm{k}$ (Tabela 1) do termorrígido e dos compósitos demonstraram que a afinidade deste materiais por água não é alta, consequência da alta cristalinidade do reforço hidrofílico $(\mathrm{CM})$ e também da boa impregnação deste material pela matriz, conforme já comentado.

Quanto maior o valor de D (Tabela 1), mais rapidamente ocorre a difusão das moléculas de água no compósito. Altos valores de $\mathrm{D}$ correspondem então a uma indicação que as interações com as moléculas de água ocorreram com menor intensidade e/ou em menor extensão, já que fortes interações entre o material e a água desaceleram a movimentação desta última, diminuindo D. Os resultados da Tabela 1 mostraram

Tabela 1. Valores de $k$ e do coeficiente de difusão, $D$, obtidos para o termorrígido (TGF) e compósitos glioxal-fenol (CGF) reforçados com 30\%, $50 \%$ e $70 \%$ de celulose microcristalina (CM). Os compósitos foram obtidos via métodos I e II (Experimental).

\begin{tabular}{lcc}
\hline \multicolumn{1}{c}{ Materiais } & $\mathbf{k}\left(\mathbf{h}^{\mathbf{2}}\right)$ & $\mathbf{D}\left(\mathbf{m m}^{\mathbf{2}} \mathbf{h}\right) \times \mathbf{1 0}^{\mathbf{3}^{*}}$ \\
\hline TGF & 0,02 & 1,1 \\
CGF- 30\% CM (II) & 0,03 & 0,8 \\
CGF- 30\% CM (I) & 0,02 & 0,4 \\
CGF- 50\% CM (I) & 0,02 & 1,6 \\
CGF- 70\% CM (I) & 0,02 & 1,0 \\
\hline
\end{tabular}

*Erro entre 1 e $16\left(\times 10^{-7}\right)$ que a introdução de $30 \%$ de celulose desacelerou um pouco a difusão das moléculas de água, comparativamente ao termorrígido (TGF) (Tabela 1), como resultado da introdução de material mais hidrofílico que a matriz, e que possui em torno de $20 \%$ de regiões não cristalinas, em que as interações com moléculas de água são facilitadas. No entanto, quando CM estava presente em proporção em massa igual (50\%) a da matriz glioxal-fenol, o coeficiente de difusão aumentou, comparativamente ao termorrígido. Neste caso, o alto teor deste polissacarídeo de alta cristalinidade levou a um material com alto conteúdo de domínios cristalinos, onde foi mais difícil a difusão de moléculas de água, devido ao eficiente empacotamento das cadeias de celulose. Este fato acelerou a movimentação das moléculas de água no material, aumentando, portanto, o valor de D. Quando a proporção de celulose aumentou para $70 \%$, a dificuldade de dispersão deste material na resina levou a um compósito com menor recobrimento do reforço pela resina, com falhas, conforme já mencionado, o que facilitou a interação com a água, levando a um valor de $\mathrm{D}$, próximo ao do termorrígido.

\section{Conclusões}

Até onde se tenha conhecimento, pela primeira vez a resina glioxal-fenol do tipo novolaca foi utilizada na preparação de compósitos. Os compósitos de matriz glioxal-fenol apresentaram boa interação fibra/matriz na interface, baixa absorção de água, estabilidade térmica compatível com muitas aplicações e elevada rigidez. O compósito glioxal-fenol reforçado com 30\% de CM adicionada no início da reação de preparação do pré-polímero (método I) foi o compósito que apresentou a menor absorção de água, comparável à do termorrígido fenólico fenol-formaldeído. Este resultado merece destaque, pois o compósito glioxal-fenol reforçado com CM corresponde a um biocompósito, com alto teor de materiais obtidos de fontes renováveis, indo ao encontro dos anseios atuais, que é de desenvolver materiais com propriedade equivalentes ou superiores àquelas dos materiais obtidos de fontes fósseis.

\section{Agradecimentos}

Os autores são gratos a FAPESP pelo auxílio financeiro e bolsa concedida a E.C.R., a CAPES/COFECUB (Projeto 422/03/05) por tornar possível o projeto entre Brasil e França e ao $\mathrm{CNPq}$ pelo auxílio financeiro e bolsa de produtividade em pesquisa concedida a E.F.

\section{Referências Bibliográficas}

1. Ramires, E. C.; Megiatto Júnior, J. D.; Gardrat, C.; Castellan, A. \& Frollini, E. - Biores. Technol., 101, p. 1998 (2010).

2. Megiatto Júnior, J. D.; Ramires, E. C. \& Frollini, E. Ind. Crops and Prod., 31, p. 178 (2010). 
3. Santos, P. A.; Spinacé, M. A. S.; Fermoselli, K. K. G. \& De Paoli, M. A. - Polímeros, 19, p. 31 (2009).

4. Ramires, E. C. \& Frollini, E. - "Celuloses como agente de reforço de matriz lignofenólica e taninofenólica", in: Anais do 9 Congresso Brasileiro de Polímeros, p. 105, Campina Grande - PB, out (2007).

5. Zárate, C. N.; Aranguren, M. I. \& Reboredo, M. M. - J. Appl. Polym. Sci., 107, p. 2977 (2008).

6. Tita, S. P. S.; Paiva, J. M. F. \& Frollini, E. - Polímeros, 12, p. 228 (2002).

7. Ku, H.; Rogers, D.; Davey, R.; Cardona, F. \& Trada, M. - J. Mater. Eng. Perform., 17, p. 85 (2008).

8. Barbosa Junior, V.; Ramires, E. C.; Oliveira, F. B. \& Frollini, E. - "Compósitos baseados em taninos, processo de produção e uso do mesmo. BR n. PI 0.801.091-9" (2008).

9. Knop, A. \& Pilato, L. A. - "Phenolic Resin", SpringerVerlag, Berlin (1985).

10. Oliveira, F. B.; Gardrat, C.; Enjalbal, C.; Frollini, E. \& Castellan, A. - J. Appl. Polym. Sci., 109, p. 2291 (2008).

11. Caliskan, M. - Turk. J. Zool., 24, p. 103 (2000).

12. Mattioda, G.; Metivier, B. \& Guetté, J. P. - L' Actualité Chimique, 5, p. 33 (1982).
13. Lei, H.; Pizzi, A. \& Du, G. - J. Appl. Polym. Sci., 107, p. 203 (2008).

14. Mathew, A. P.; Oksman, K. \& Sain, M. - J. Appl. Polym. Sci., 97, p. 2014 (2005).

15. Paiva, J. M. F.; Trindade, W. G. \& Frollini, E. - Polímeros, 9, p. 170 (1999).

16. Ramires, E. C. \& Frollini, E. - "Renewable resources as reinforcement of lignophenolic and tanninphenolic matrices", in: Proceedings of the 9 Conference of Science and Wood Industries, p. 1, Bordeaux, nov (2008).

17. ASTM INTERNATIONAL - "ASTM D570-98: standard test method for water absorption of plastics", West Conshohocken (2006).

18. Scheirs, J.; Camino, G. \& Tumiati, W. - Eur. Polym. J., 37, p. 933 (2001).

19. Espert, A.; Vilaplana, F. \& Karlsson, S. - Compos. Appl. Sci. Manuf., 35, p. 1267 (2004).

Enviado: 10/11/09

Reenviado: $18 / 01 / 10$

Aceito: $29 / 01 / 10$

DOI: $10.1590 / \mathrm{S} 0104-14282010005000016$ 